\title{
Effect of Biochar Application on Physicochemical and Hydraulic Properties of Loess
}

\author{
Xiujuan Yang (iD, Henghui Fan $(\mathbb{D}$, Yuhang Du, and Lu Zhang \\ College of Water Resources and Architectural Engineering, Northwest A\&F University, Yangling, Xianyang 712100, China \\ Correspondence should be addressed to Henghui Fan; yt07@nwsuaf.edu.cn
}

Received 1 November 2019; Revised 21 April 2020; Accepted 17 June 2020; Published 18 August 2020

Academic Editor: Annan Zhou

Copyright (c) 2020 Xiujuan Yang et al. This is an open access article distributed under the Creative Commons Attribution License, which permits unrestricted use, distribution, and reproduction in any medium, provided the original work is properly cited.

Biochar is important for optimizing soil physical structure and improving soil water retention. The saturated water capacity test, water repellency test, and permeability coefficient test were used to study the effects of biochar additive amount $(0,2,5$, 10,15 , and $20 \mathrm{~g} / \mathrm{kg}$ ) and particle size $(>2 \mathrm{~mm}, 2 \mathrm{~mm}-0.075 \mathrm{~mm}$, and $<0.075 \mathrm{~mm})$ on the basic physicochemical and hydraulic properties of loess. The results showed that with the increase of biochar additive content, the relative particle density decreased linearly $\left(R^{2}=0.984\right)$; the plastic limit, liquid limit, and plasticity index increased $\left(R^{2}=0.947,0.991\right.$, and 0.984 , respectively); the maximum dry density decreased $\left(R^{2}=0.900\right)$; and the optimal water content and saturated water content increased gradually. At the same time, the soil's $\mathrm{pH}$ increased $\left(R^{2}=0.957\right)$, the soil water repellency decreased, and the water infiltration became easier, but the soil's permeability coefficient (saturated water conductivity) decreased. When the the biochar particles size is smaller, the soil's water repellency and permeability coefficient reduced. Studies had shown that the application of biochar makes the loess infiltrate easily, seepage slowly, and contain more water, which improve the water infiltration characteristics and water retention capacity of loess.

\section{Introduction}

Biochar refers to a kind of solid insoluble matter produced by the carbonization of agricultural and forestry wastes [1]. It shows strong adsorption, has high activity, and is a potential soil improver [2]. Previous studies had shown that biochar has the effect of improving soil quality, changing soil bulk density and porosity, increasing soil aggregate structure, and improving soil hydrodynamic effects [3-5] and has a significant impact on rainfall erosion [6]. Biochar is alkaline and has a significant effect in acid soil improvement [7]. Yanli et al. [8] have proved that acidified biochar can effectively reduce the $\mathrm{pH}$ value of soda saline soil. Biochar also effectively inhibits the accumulation of salt in the soil surface [9].

Most of the soil in the loess region of northwest China is loose, and the water retention capacity of the soil is weak, which makes more serious soil erosion in this area. Through the soil column experiment, Tan et al. [10] found that as the nanocarbon content increases, the saturated mass water content of the disturbed loess soil increases and the saturated hydraulic conductivity decreases. Xin-xiang et al. [11] found that biochar can absorb and retain moisture. Rui-peng et al. [12] found that biochar can increase the infiltration capacity of anthrosol and reduce the infiltration capacity of aeolian sandy soil. Liu et al. [13] found that high intraporosity and an irregular shape of biochar can effectively improve the water retention of sandy soils. After the addition of biochar, the runoff yielding time can be delayed and the amount of erosion can be reduced, but the role of biochar is relatively weak [6]. Ni found that by adding $10 \%(\mathrm{v} / \mathrm{v})$ of biochar, the optimum water content of soil increased from 12 to $17 \%$, while the maximum dry density decreased from 1890 to $1740 \mathrm{~kg} / \mathrm{m}^{3}$ [14]. Garg proposed biochar as an alternative soil amendment in landfill cover and found that the presence of biochar increased soil water content and the increased amount was almost the same over a wide range of suction values [15]. In summary, it can be found that different biochar addition amounts and different particle sizes have significant effects on soil water characteristics. 
In this paper, the effects of different amounts of biochar and different particle sizes on the physicochemical and hydraulic properties of typical loess in semiarid areas were studied by the saturated water content test, water repellency test, and permeability coefficient experiment. It is proposed to provide scientific basis for soil erosion and other aspects.

\section{Materials and Methods}

2.1. Materials. The loess used in this experiment was $\mathrm{Q}_{4}$ loess, taken from the loess terrace-like plain area of Yangling, Shaanxi. The soil depth is $0.5-1.5 \mathrm{~m}$, and the soil is brownish yellow with a uniform texture. After collection, the grass roots and other debris were removed, naturally air dried and crushed, and then passed through a $2 \mathrm{~mm}$ sieve. The relative density of the particles was 2.71 , and the undisturbed soil's moisture content is $13.1 \%$. In addition, the dry density of the natural Loess is $1.36 \mathrm{~g} / \mathrm{cm}^{3}$, and the void ratio is 0.98 . The basic physical and chemical indicators of soil samples are shown in Table 1.

The biochar was selected from the rice husk charcoal, which was provided by Jinan Yihe Century Landscaping Co., Ltd. The biochar had a relative density of 0.45 and a $\mathrm{pH}$ of 10.09, and was alkaline. In the biochar pulverization sample, the particle group of $>2 \mathrm{~mm}$ accounted for $12.68 \%$, the grain group of $2 \mathrm{~mm}-0.075 \mathrm{~mm}$ accounted for $85.29 \%$, and the particle group of $<0.75 \mathrm{~mm}$ accounted for $2.03 \%$.

\subsection{Methods}

2.2.1. Test Plan. Soils were uniformly mixed with biochars at contents of $0 \mathrm{~g} / \mathrm{kg}, 2 \mathrm{~g} / \mathrm{kg}, 5 \mathrm{~g} / \mathrm{kg}, 10 \mathrm{~g} / \mathrm{kg}, 15 \mathrm{~g} / \mathrm{kg}$, and $20 \mathrm{~g} /$ $\mathrm{kg}$ for the purpose of studying the effect of different contents of biochar on soil properties. Soils were uniformly mixed with $>2 \mathrm{~mm}, 2-0.075 \mathrm{~mm}$, and $<0.075 \mathrm{~mm}$ biochars for the purpose of studying the effect of biochar particle size on soil properties. The prepared sample had a water content of $19.0 \%$ (optimal moisture content of Yangling loess) and a dry density of $1.38 \mathrm{~g} / \mathrm{cm}^{3}$ (close to the natural loess's dry density), $1.48 \mathrm{~g} / \mathrm{cm}^{3}$, and $1.58 \mathrm{~g} / \mathrm{cm}^{3}$ (the maximum of Yangling loess dry density $\times 0.90$ compaction).

2.2.2. Routine Tests. The experiments include the particle relative density test, boundary moisture test, compaction test, $\mathrm{pH}$ test, and permeability coefficient test. These tests were carried out in accordance with the test methods specified in the Geotechnical Test Specification (SL2371999). Among them, the boundary water content test used the liquid-plastic limit combined measuring instrument, the compacting test used the light compacting instrument, the $\mathrm{pH}$ test used the electric measuring method, and the permeability coefficient test used the variable water head method.

2.2.3. Soil Water Repellency Test. Soil water repellency refers to the fact that certain soils cannot be wetted by water. When water drops on the surface of the soil with water repellency, the water droplets will stay on the surface of the soil for a while. These water droplets are not infiltrated for a long time, and their resistance to wetting varies from hours to weeks.

In this paper, the water repellency of soil was tested by the drip penetration time method [16]. According to the test scheme, the homogeneous mixed soil samples with the same initial moisture content and different dry densities were pressed into cutting rings. The distilled water droplets were sucked up on the surface of the soil sample by using a pipette, and the infiltration time from the contact of the water droplets with the surface of the soil to the complete penetration was recorded. In order to reduce the influence of kinetic energy of water droplets, the distance between the mouth of the drip tube and the surface of the soil sample should be controlled to about $1 \mathrm{~cm}$. Each soil sample was repeatedly measured 4 times at different positions, and the average value of the complete infiltration time was taken as the drip infiltration time of the soil sample.

2.2.4. Soil Water Capacity Test. Saturated water content, also known as saturated water capacity and water holding capacity, is the ratio of the mass of water to the mass of solid particles when the soil pores are completely filled with water, expressed as a percentage [17]. The uniformly mixed soil samples were pressed into three-axis molds according to different dry densities and placed them in a soil sample saturators. The soil sample was vacuum-saturated and then flooded in water for $48 \mathrm{~h}$. The soil sample was carefully taken out, weighed, and then dried and weighed for the purpose of calculating the saturated moisture content of the soil sample. Three parallel samples were prepared for each soil sample, and the average value was taken as the saturated water content of the soil sample.

\section{Results and Analysis}

3.1. Effect of Biochar Content on Physical Properties of Soil Samples. Table 2 shows the relative particle density values ranged from 2.71 to 2.20 for the $20 \mathrm{~g} / \mathrm{kg}$ biochar amended soil.

The regression equation for relative particle density as a function of the biochar amendment rate was determined as shown in the following equation:

$$
\begin{aligned}
\text { relative particle density }= & -0.105 \times(\mathrm{g} / \mathrm{kg} \text { biochar }) \\
& +2.806 \quad\left(R^{2}=0.984\right) .
\end{aligned}
$$

It is clear that the relative particle density value ranges from 2.71 to 2.20 , decreasing with increasing biochar content from $0 \mathrm{~g} / \mathrm{kg}$ to $20 \mathrm{~g} / \mathrm{kg}$. This is due to differences in physical properties of biochar and soil. The relative density of biochar is 0.45 , and when it is incorporated into the soil, it occupies a part of the space of the particles. As the proportion of biochar in the soil increases, the amount of soil particles decreases relatively and the relative particle density of biochar mixed with soil decreases.

The boundary water content of soil is an important indicator for the division of soil state, and the liquid plastic 
TABLE 1: The parameters of the loess.

\begin{tabular}{|c|c|c|c|c|c|c|c|c|c|c|c|}
\hline $\begin{array}{l}\text { Liquid } \\
\text { limit } \\
(\%)\end{array}$ & $\begin{array}{c}\text { Plastic } \\
\text { limit } \\
(\%)\end{array}$ & $\begin{array}{c}\text { Plasticity } \\
\text { index }\end{array}$ & $\begin{array}{l}\text { Maximum } \\
\text { dry density } \\
\quad\left(\mathrm{g} / \mathrm{cm}^{3}\right)\end{array}$ & $\begin{array}{l}\text { Optimum } \\
\text { moisture } \\
\text { content } \\
(\%)\end{array}$ & $2-0.075 \mathrm{~mm}$ & $0.075-0.005 \mathrm{~mm}$ & $<0.005 \mathrm{~mm}$ & $\mathrm{pH}$ & $\begin{array}{c}\text { Organic } \\
\text { matter } \\
(\mathrm{g} / \mathrm{kg})\end{array}$ & $\begin{array}{l}\text { Soluble } \\
\text { salt (g/ } \\
\text { kg) }\end{array}$ & $\begin{array}{l}\text { Insoluble } \\
\text { salt }(\mathrm{g} / \mathrm{kg})\end{array}$ \\
\hline 36.3 & 20.7 & 15.6 & 1.74 & 19.03 & 0.81 & 74.18 & 25.01 & 8.63 & 5.06 & 0.16 & 84.98 \\
\hline
\end{tabular}

TABLE 2: Effect of biochar content on physical and chemical properties of soil.

\begin{tabular}{|c|c|c|c|c|c|}
\hline Biochar application $(\mathrm{g} / \mathrm{kg})$ & Relative particle density & Plastic limit (\%) & Liquid limit (\%) & Plastic index & $\mathrm{pH}$ value \\
\hline 0 & 2.71 & 20.68 & 36.30 & 15.62 & 8.63 \\
\hline 2 & 2.62 & 20.91 & 37.14 & 16.23 & 8.63 \\
\hline 5 & 2.45 & 20.96 & 37.90 & 16.94 & 8.64 \\
\hline 10 & 2.37 & 21.33 & 38.64 & 17.31 & 8.67 \\
\hline 15 & 2.29 & 21.73 & 39.36 & 17.63 & 8.68 \\
\hline 20 & 2.20 & 22.17 & 40.61 & 18.44 & 8.71 \\
\hline
\end{tabular}

limit of soil is often used as an indicator to assess soil erosion vulnerability and shallow surface movement [18]. Unlike the relative particle density, plastic limit increased with the application of biochar amendment. The lowest plastic limit was $20.68 \%$ for the nonamended soil, increasing to $20.91 \%$, $20.96 \%, 21.33 \%, 21.73 \%$, and $22.17 \%$, respectively. The plastic limit is related to the rate of biochar amendment by the following equation:

$$
\text { plastic limit }=0.294 \times(\mathrm{g} / \mathrm{kgbiochar})+20.269\left(R^{2}=0.947\right) \text {. }
$$

Just like plastic limit, the liquid limit and the plasticity index are also related to the rate of biochar amendment by the following equation:

liquid limit $=0.827 \times(\mathrm{g} / \mathrm{kgbiochar})+35.430\left(R^{2}=0.991\right)$,

plasticity index $=0.533 \times(\mathrm{g} / \mathrm{kgbiochar})+15.161\left(R^{2}=0.984\right)$.

The regression equation in plastic limit reveals a significant increase as the rate of biochar amendment increased. Equations (3) and (4) also demonstrate that the liquid limit and plasticity index have the same tendency. With the increasing of biochar additive, the fine particles in the soil gradually increased. The specific surface area of the biochar is larger than the soil, resulting in a larger range of soil water content in the plastic state. And then, the water holding capacity is increased.

The results of the compaction experiment (Figure 1) show that as the biochar content increases, the compaction curve of the soil shifts to the right and the peak gradually decreases. The maximum dry density of the soil decreased from $1.74 \mathrm{~g} / \mathrm{cm}^{3}$ to $1.66 \mathrm{~g} / \mathrm{cm}^{3}$. The optimum moisture content gradually increased from $19.0 \%$ to $21.8 \%$. The linear decrease in maximum dry density as a function of biochar application rate is represented by the following:

$$
\begin{aligned}
\text { the maximum dry density }= & -0.015 \times(\mathrm{g} / \mathrm{kg} \text { biochar }) \\
& +1.741\left(R^{2}=0.900\right) .
\end{aligned}
$$

And the linear increase in optimum moisture content as a function of biochar application rate is showed by the following equation:

$$
\begin{aligned}
\text { the optimum moisture content }= & 0.630 \times(\mathrm{g} / \mathrm{kg} \text { biochar }) \\
& +17.749\left(R^{2}=0.942\right) .
\end{aligned}
$$

Due to the incorporation of biochar, the structure of the nonamended soil is looser than amended soil and it is not easy to compact. In this case, the water holding capacity of the soil is enhanced.

3.2. Effect of Biochar Content on $p H$ Values. Since biochar is rich in calcium and alkaline, the application of biochar can effectively regulate acid and is a very effective soil acid neutralizer [19]. At the same time, the long-term use of biochar can replace sodium ions to reduce the alkalization hazard and has certain effects on the improvement of saline soil and alkaline soil [20]. In this test, the time effect was not considered. The $\mathrm{pH}$ value of the mixed soil sample was tested (Table 2). With the increase of the amount of biochar, the $\mathrm{pH}$ value of the soil sample increases; the equation is as follows:

$$
\mathrm{pH} \text { value }=0.016 \times(\mathrm{g} / \mathrm{kgbiochar})+8.600\left(R^{2}=0.957\right) .
$$

The regression equation reveals a significant increase in $\mathrm{pH}$ value as the rate of biochar amendment increases. While the overall range of the $\mathrm{pH}$ value is between 8.63 and 8.71 , the study in [8] found that acidified biochar can effectively reduce the $\mathrm{pH}$ value of soda saline-alkaline soil and alkaline biochar also has the effect of lowering the $\mathrm{pH}$ value of saline soil [21]. In this test, the $\mathrm{pH}$ of the biochar was 10.09 and the loess's $\mathrm{pH}$ was 8.63. In short-term action, the biochar did not work on the soil, so the results just represented the mixture's $\mathrm{pH}$, not included the physicochemical action of the biochar 


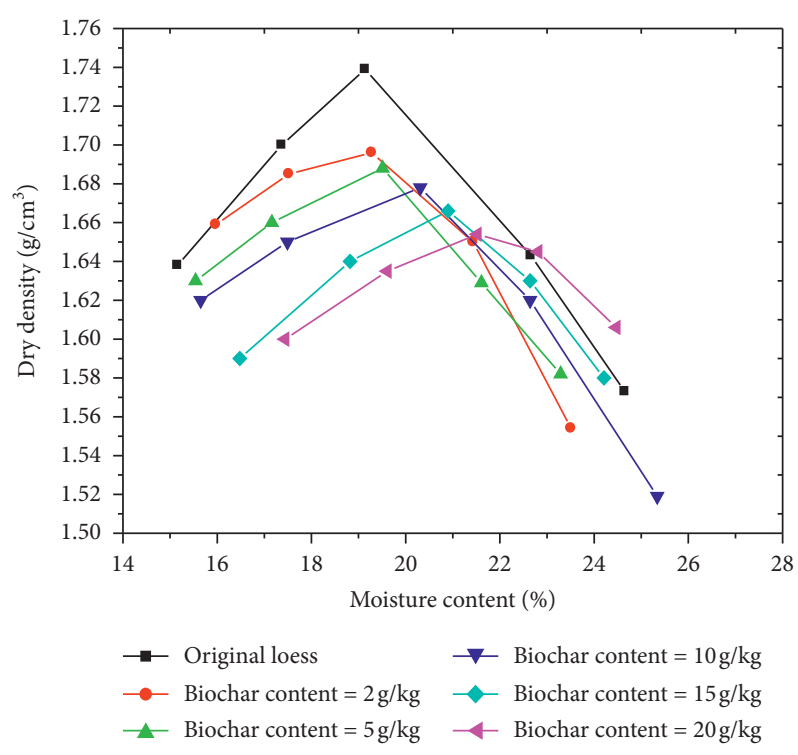

FIGURE 1: The variation of soil $\rho_{\mathrm{dmax}}$ and $\mathrm{w}_{\mathrm{op}}$.

on the soil. For long-term reactions, follow-up experiments are also required.

\subsection{Effect of Biochar Content on Saturated Moisture Content of} Soil Samples. Water holding capacity is one of the physical properties of the soil. And the saturated water content is an important index of the maximum water holding capacity of soil. The relationship between the measured saturated water content of the soil and the biochar content, the dry density of the soil is plotted in Figure 2. It can be seen that as the dry density of the soil increases, the saturated water content decreases. The internal porosity reduces because of high density, and thus, the amount of stored water decreases when saturated. At the same time, the curves of the saturated water content of soil with increasing dry density under the action of different biochars are basically parallel. It means that biochar application has a significant improvement in the water retention capacity of the soil.

\subsection{Effect of Biochar Content and Particle Size on Soil Water} Repellency. Soil water repellency is related to soil organic matter, water content, $\mathrm{pH}$, temperature, chemical composition, soil structure, compactness, and other factors [22, 23]. In this study, the initial soil moisture content of the control soil was described, and the relationship between water infiltration time and biochar content was obtained using three different dry density samples (Figure 3). Under the same conditions, the dry density has a greater impact on the infiltration time. Taking pure loess as an example, the infiltration time of water droplets increases linearly from $5.49 \mathrm{~s}$ $\left(1.38 \mathrm{~g} / \mathrm{cm}^{3}\right)$ to $68.8 \mathrm{~s}\left(1.58 \mathrm{~g} / \mathrm{cm}^{3}\right)$, which is about 11 times. However, this effect of dry density gradually decreases as the amount of biochar blending increases.

With the increase of biochar addition, the infiltration time of water droplets of all soil samples gradually decreases. The greater the dry density of the soil sample, the greater the

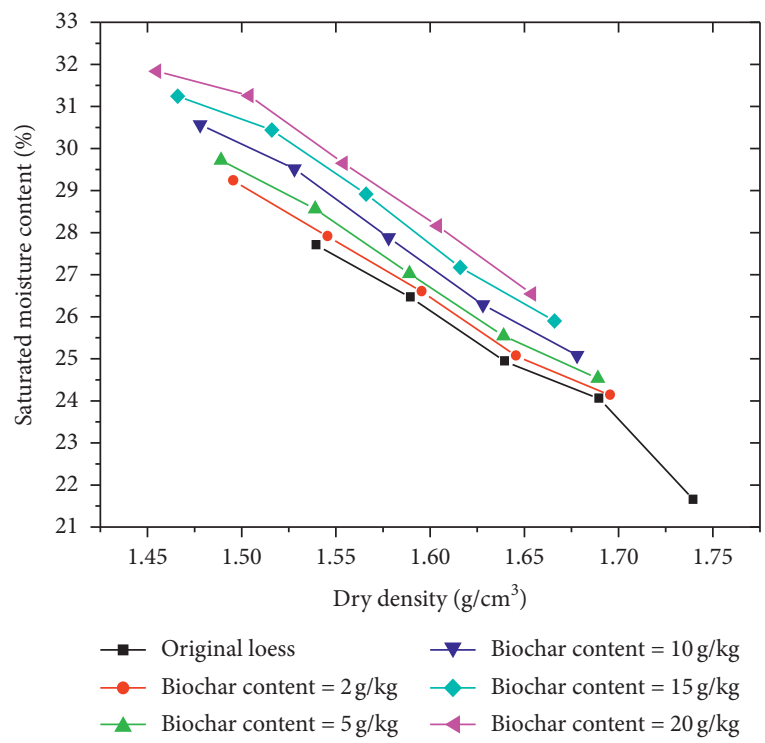

FIGURE 2: The variation of soil saturated moisture content.

rate of decline. It is generally believed that the soil with drip infiltration time exceeds $5 \mathrm{~s}$ and the soil has water repellency. If the drip infiltration time is $5-60 \mathrm{~s}$, the soil has slight water repellency, if the drip infiltration time is 60-600 s, the soil has strong water repellency, and if the drip infiltration time is more than $3600 \mathrm{~s}$, the soil is considered to have extreme water repellency [24]. It can be seen that when the soil sample is dense, the water is difficult to infiltrate, and the soil sample has strong water repellency. After the biochar is added, the water repellency is gradually reduced. When the soil sample density is small, the soil sample is changed from slightly water repellent to nonwater repellent.

For the aspect of biochar particle size, when incorporating coarse-grained biochar, the infiltration time of water droplets is greater than the infiltration time of water droplets when 


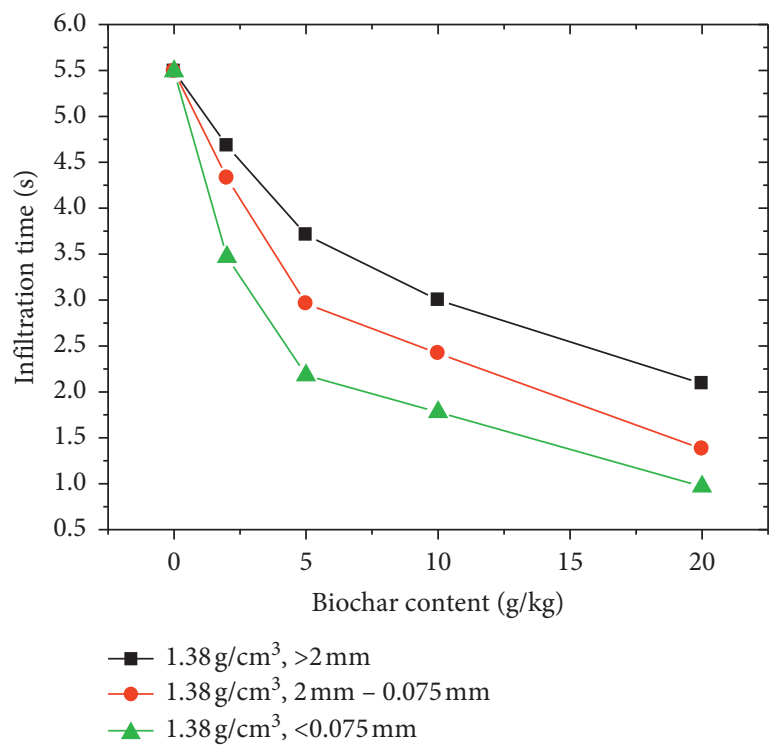

(a)

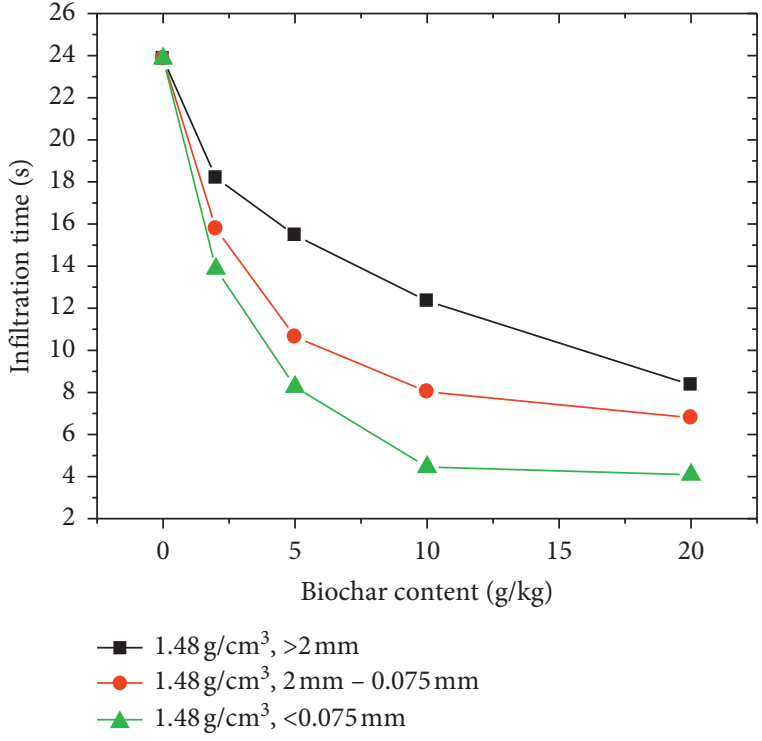

(b)

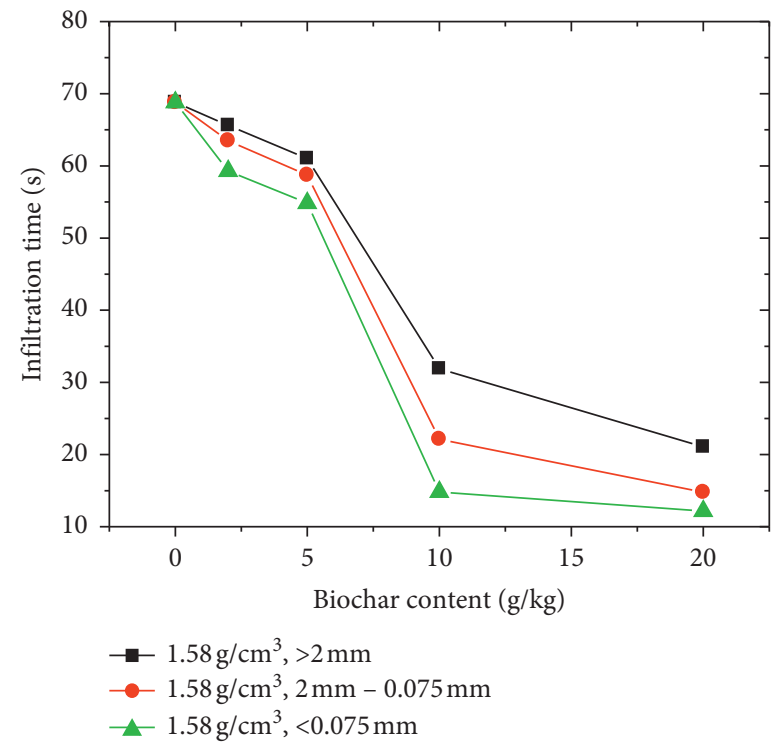

(c)

Figure 3: The variation of soil infiltration time with the amount of biochar (a) for $\rho=1.38 \mathrm{~g} / \mathrm{cm}^{3}$, (b) for $\rho=1.48 \mathrm{~g} / \mathrm{cm}^{3}$, and (c) for $\rho=1.58 \mathrm{~g} /$ $\mathrm{cm}^{3}$.

mixed with fine-grained biochar. It is indicated that the effect of coarse-grained biochar on soil water repellency should be improved. Compared with coarse-grained biochar, finegrained biochar is more likely to interact with soil particles and form soil aggregates [25], which promotes an increase in soil porosity and reduces the water repellency of the soil.

3.5. Effect of Biochar Content and Particle Size on Soil Permeability. The permeability coefficient (saturated water conductivity) of soil is directly related to the number of pores in the soil, the structure of the soil, and the texture. The permeability change of soil after adding biochar of different contents and particle sizes is shown in Figure 4. Under the same conditions, the dry density has a great influence on the infiltration time. With the increase of biochar addition, the permeability coefficient of soil gradually decreases, indicating that biochar treatment significantly inhibited the infiltration capacity of loess, which is consistent with the research in [26]. At the same time, from the perspective of biochar particle size, the coarse-grained biochar has a lower permeability to soil than the fine-grained biochar, which is not consistent with the studies in $[27,28]$. This is due to the different study objects used in the test. The loess used in the test is mainly composed of fine particles including very little calcareous sand. The difference in particle size between the three soils is significant, so the conclusions are not consistent. 


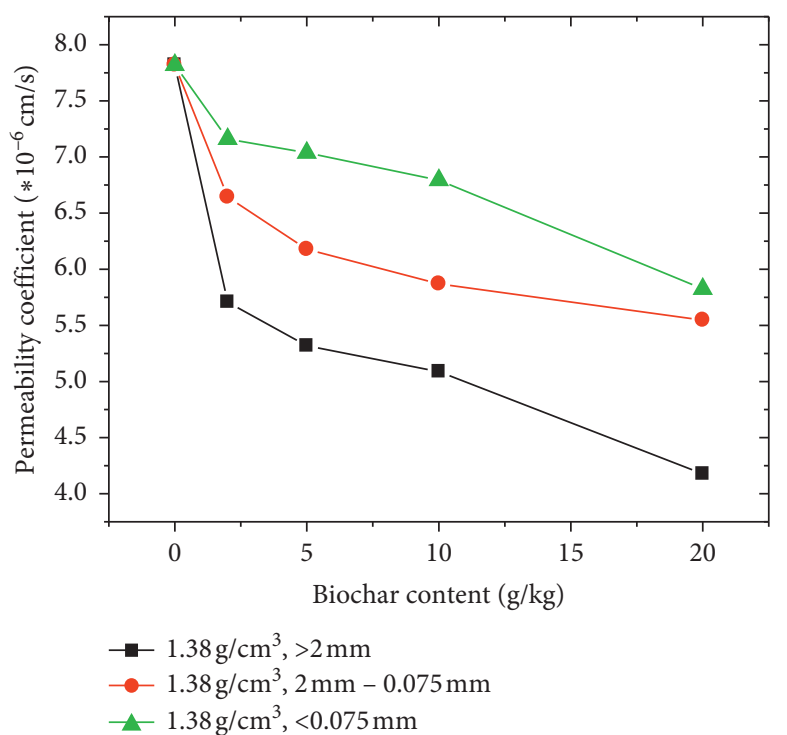

(a)

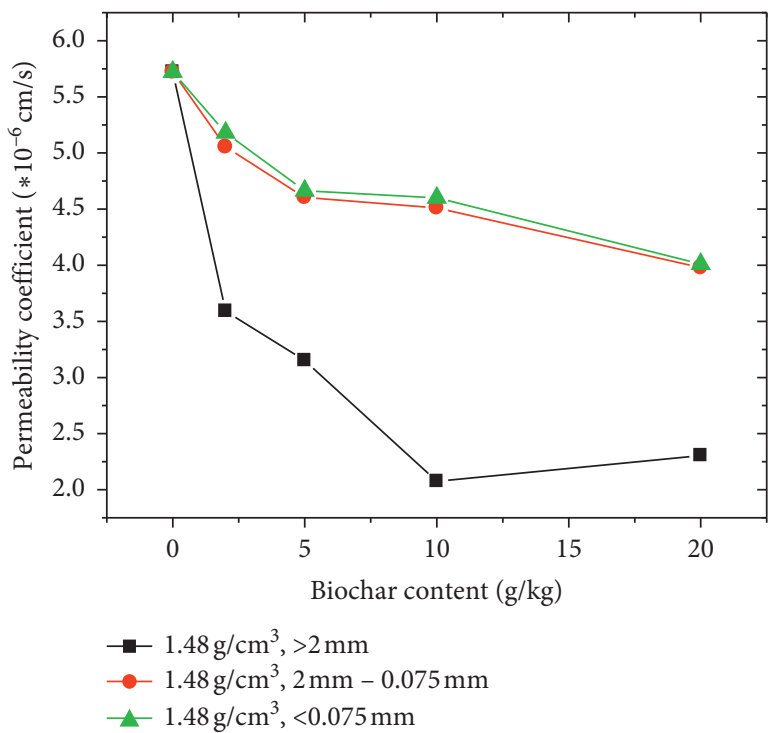

(b)

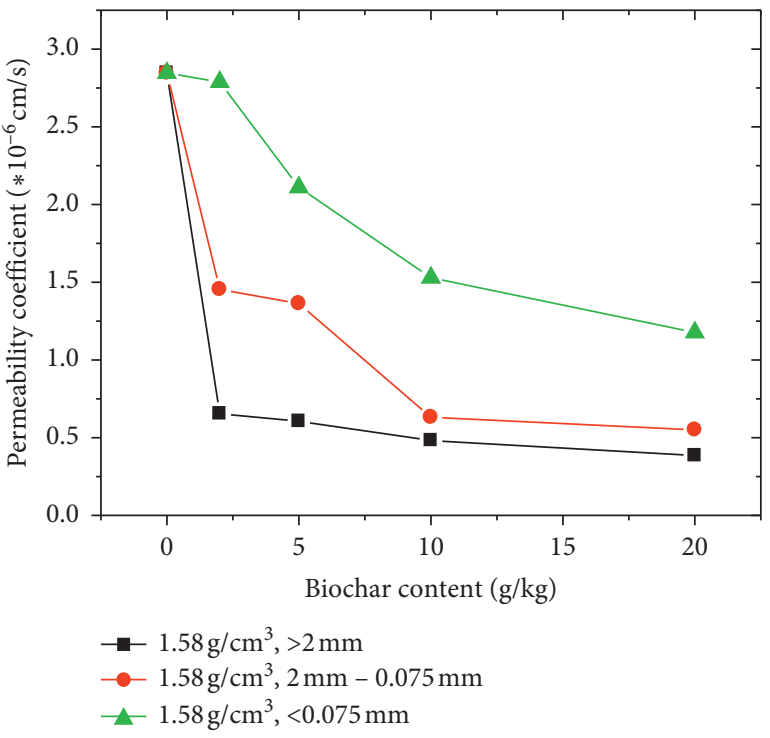

(c)

Figure 4: The variation of soil permeability coefficient (a) for $\rho=1.38 \mathrm{~g} / \mathrm{cm}^{3}$, (b) for $\rho=1.48 \mathrm{~g} / \mathrm{cm}^{3}$, and (c) for $\rho=1.58 \mathrm{~g} / \mathrm{cm}^{3}$.

\section{Conclusions}

Experimental results from this study show that biochar addition has a positive impact on the physicochemical and hydraulic properties of loess. The relative density and maximum dry density of soil particles were significantly reduced by the application of biochar. However, the soil's alkali value, the boundary moisture content, the optimal water content and the saturated water content of the soil were significantly improved by biochar at all, and also the water capacity of soil. The soil's hydrophobicity was reduced by the biochar, and in this way, it became easier for water penetration. But the soil's permeability coefficient (saturated hydraulic conductivity) decreased. In this case, the water migrated slowly through the soil and the soil maintained its enhanced water absorption capacity. The hydraulic properties of loess were affected by the added biochar size. When the size is larger, the soil's water repellency increased, and it has a greater decrease in permeability coefficient.

\section{Data Availability}

The data used to support the findings of this study are available from the first author upon request.

\section{Conflicts of Interest}

The authors declare that there are no conflicts of interest.

\section{Acknowledgments}

This research was financially supported by the Yangling Science and Technology Project (Grant no. 2018NY-28) and 
the Natural Science Basic Research Plan in Shaanxi Province of China (Grant no. 2020JQ-278). The authors also thank the Shaanxi Postdoctoral Research Funding Project (Grant no. 2018BSHEDZZ23). And sincere thanks are due to LIU Kaiming and JIANG Kai who devoted themselves in this report.

\section{References}

[1] M. J. Antal and M. Grønli, "The art, science, and technology of charcoal production $\dagger$," Industrial \& Engineering Chemistry Research, vol. 42, no. 8, pp. 1619-1640, 2003.

[2] W. I. Woods, N. P. S. Falcão, W. G. Teixeira et al., "Biochar trials aim to enrich soil for smallholders," Nature, vol. 443, no. 7108, p. 144, 2006.

[3] K. Jindo, M. A. Sánchez-Monedero, T. Hernández et al., "Biochar influences the microbial community structure during manure composting with agricultural wastes," Science of the Total Environment, vol. 416, pp. 476-481, 2012.

[4] X. H. Liu, F. P. Han, and X. C. Zhang, "Effect of biochar on soil aggregates in the loess plateau: results from incubation experiments," International Journal of Agriculture and Biology, vol. 14, no. 6, pp. 975-979, 2012.

[5] G. S. Pardo, A. K. Sarmah, and R. P. Orense, "Mechanism of improvement of biochar on shear strength and liquefaction resistance of sand," Géotechnique, vol. 69, no. 6, pp. 471-480, 2019.

[6] W. Yuan-yuan, Y. Ming-yi, F.-B. Zhang et al., "Effect of biochar application on erodibility of plow layer on loess slopes," Acta Pedologica Sinica, vol. 53, no. 1, pp. 81-92, 2016.

[7] M. F. Qayyum, I. Ashraf, M. Abid, and D. Steffens, "Effect of biochar, lime, and compost application on phosphorus adsorption in a Ferralsol," Journal of Plant Nutrition and Soil Science, vol. 178, no. 4, pp. 576-581, 2015.

[8] Y. Yan-li, L. Xiu-jun, C. Guo-shuang et al., "Effects of biochar on saline-sodic soil physical and chemical properties," Soil and Crop, vol. 4, no. 3, pp. 113-119, 2015.

[9] S. Yun-peng, Y. Jin-song, R.-J. YAO et al., "Biochar and chemical fertilizer application on soil properties in farmland reclaimed from salinity tidal flat," Chinese Journal of Soil Science, vol. 48, no. 2, pp. 454-459, 2017.

[10] S. TAN, Z. Bei-bei, and Q.-J. WANG, "Effects on nano-carbon on water infiltration process in disturbed loessal soil," Acta Pedologica Sinica, vol. 51, no. 2, pp. 263-268, 2014.

[11] C. Xin-xiang, H. Xu-sheng, W. ZHANG et al., "Effects of quantity of biochar on nitrogen leaching in simulated soil columns and soil moisture parameters in field," Agricultural Research in the Arid Areas, vol. 32, no. 1, pp. 110-114, 2014.

[12] Q. I. Rui-peng, L. ZHANG, Y.-H. YAN et al., "Effects of biochar addition into soils in semiaris land on water infiltration under the condition of the same bulk density," Chinese Journal of Applied Ecology, vol. 25, no. 8, pp. 2281-2288, 2014.

[13] Z. L. Liu, B. Dugan, C. A. Masiello et al., "Biochar particle size, shape, and porosity act together to influence soil water properties," PLoS One, vol. 12, no. 6, Article ID e0179079, 2017.

[14] J. J. Ni, X. W. Chen, C. W. Ng, and H. W. Guo, "Effects of biochar on water retention and matric suction of vegetated soil," Géotechnique Letters, vol. 8, no. 2, pp. 124-129, 2018.

[15] A. Garg, S. Bordoloi, J. Ni et al., "Influence of biochar addition on gas permeability in unsaturated soil," Géotechnique Letters, vol. 9, no. 1, pp. 66-71, 2019.
[16] W. Van't and D. Bessel, "Particle coatings affecting the wettability of soils," Journal of Geophysical Research, vol. 64, no. 2, pp. 263-267, 1959.

[17] L. Jia-cheng, Soil Agrochemical Analysis Handbook, p. 12, China Agriculture Press, Beijing, China, 1988.

[18] S. Stanchi, M. Freppaz, and E. Zanini, "The influence of Alpine soil properties on shallow movement hazards, investigated through factor analysis," Natural Hazards and Earth System Sciences, vol. 12, no. 6, pp. 1845-1854, 2012.

[19] T. Wang, C. E. Stewart, C. Sun, Y. Wang, and J. Zheng, "Effects of biochar addition on evaporation in the five typical Loess Plateau soils," Catena, vol. 162, pp. 29-39, 2018.

[20] J.-H. Yuan, R.-K. Xu, and H. Zhang, "The forms of alkalis in the biochar produced from crop residues at different temperatures," Bioresource Technology, vol. 102, no. 3, pp. 3488-3497, 2011.

[21] W. Zhang, G. Zeng-chao, C. Xin-xiang et al., "Effects of biochar on saline soil improvement," Agricultural Research in the Arid Areas, vol. 31, no. 2, pp. 73-77+105, 2013.

[22] Y. Song, J.-H WU, H.-Y DONG et al., "Soil water repellency of sands and clay as affected by particle size," Acta Pedologica Sinica, vol. 53, no. 2, pp. 421-426, 2016.

[23] D. Diehl, "Soil water repellency: dynamics of heterogeneous surfaces," Colloids and Surfaces A: Physicochemical and Engineering Aspects, vol. 432, no. 2, pp. 8-18, 2013.

[24] J. Letey, M. Carrillo, and X. Pang, "Approaches to characterize the degree of water repellency," Journal of Hydrology, vol. 231232, pp. 61-65, 2000.

[25] H. Herath, M. Camps-Arbestain, and M. Hedley, "Effect of biochar on soil physical properties in two contrasting soils: an Alfisol and an Andisol," Geoderma, vol. 209-210, pp. 188-197, 2013.

[26] X. Qian, W. Li-mei, Q. Rui-peng et al., "Effects of biochar on water infiltration and water holding capacity of loessial soil," Journal of Earth Environment, vol. 7, no. 1, pp. 65-76+86, 2016.

[27] L. Esmaeelnejad, M. Shorafa, M. Gorji, and S. m. Hosseini, "Impacts of woody biochar particle size on porosity and hydraulic conductivity of biochar-soil mixtures: an incubation study," Communications in Soil Science and Plant Analysis, vol. 48, no. 14, pp. 1710-1718, 2017.

[28] A. Ibrahim, A. R. Usman, M. I. Al-Wabel et al., "Effects of conocarpus biochar on hydraulic properties of calcareous sandy soil: influence of particle size and application depth," Archives of Agronomy and Soil Science, vol. 63, 2017. 